\title{
Review of: "Process Optimization for Biosynthesis of Pyruvate Decarboxylase (PDC) and Neuberg's Ketol (PAC) from Novel Pichia Cecembences Through Response Surface Methodology using Industrial Waste as Substrate"
}

\author{
Neeta Kumari ${ }^{1}$ \\ 1 Birla Institute of Technology, Mesra
}

Potential competing interests: The author(s) declared that no potential competing interests exist.

There are some spelling and sentence making issue

In section 3.4 : Evaluation of RSM "Designe"

where the Designe should be Design

In section 5 Pdc is written in place of PDC

Tables and figures should be properly drawn

In the paper why PBM method is used is not explained.

The ANOVA results, the way it is sited in section 3.5 can be dealt with the reference of table number I could not find the equation number in the text.

The paper with proper formatting and revision can be accepted 